\title{
Characterization of the Internalization of Bacillus Calmette-Guerin by Human Bladder Tumor Cells
}

\author{
Kanami Kuroda, " Eric J. Brown," W. Brian Telle, ${ }^{* 8}$ David G. Russell," and Timothy L. Ratliff** \\ *Toho University School of Medicine, Department of Urology, Ohta-Ku, Tokyo 143, Japan; ${ }^{\ddagger}$ The Jewish Hospital of St. Louis, \\ Department of Surgery (Urology), St. Louis, Missouri 63110; and ${ }^{\boldsymbol{s}}$ Washington University School of Medicine, Departments of \\ 'Medicine, 'Molecular Microbiology, and ${ }^{* *}$ Department of Pathology, St. Louis, Missouri 63110
}

\begin{abstract}
Adjuvant intravesical Mycobacterium bovis BCG is the treatment of choice for recurrent superficial bladder cancer. Fibronectin (FN) was previously demonstrated to be necessary for the retention of $\mathrm{BCG}$ within the bladder and for the expression of antitumor activity. Recent studies have demonstrated that BCG attach and are ingested by bladder epithelial cells, suggesting the existence of a second bacterial attachment mechanism. We report the characterization of the molecules involved in BCG attachment and internalization by the human bladder transitional cell carcinoma cell line T-24. Pretreatment of T-24 cells with monoclonal antibodies to either $\alpha_{5}$ or $\beta_{1}$ integrin subunits significantly inhibited both BCG attachment and ingestion. Exogenous FN was observed to enhance both attachment and ingestion of BCG, and anti-FN was observed to inhibit both phenomena. Latex beads precoated with either FN or laminin (LN) but not BSA were ingested by T-24 cells, but only FNcoated beads inhibited BCG attachment and ingestion. Pretreatment of BCG with FN augmented both attachment and ingestion. The role of bacterial FN binding proteins was evaluated. A monoclonal antibody to a 55-kD FN-binding protein was observed to abrogate attachment and ingestion.

These results demonstrate that attachment and ingestion of BCG are mediated in part by the $\alpha_{5} \beta_{1}$ integrin receptor and are dependent on FN. These studies demonstrate a mechanism of entrance of mycobacteria into epithelial cells and suggest a second role for FN in the adjuvant antitumor effect of BCG. ( $J$. Clin. Invest. 1993. 91:69-76.) Key words: immunotherapy • bladder cancer - bacillus Calmette-Guerin - pathogenicity • phagocytosis
\end{abstract}

\section{Introduction}

In 1976, Morales and associates first reported the efficacy of adjuvant intravesical BCG for superficial bladder cancer (1). Since the initial report, prospective randomized studies have demonstrated BCG to be superior to surgery alone (2), adjuvant thiotepa (3), and adjuvant Adriamycin (4, 5). Although the efficacy of BCG is clearly established, the mechanisms by

Address correspondence and reprint requests to Timothy Ratliff, Ph.D., Department of Surgery, The Jewish Hospital of St. Louis, 216 South Kingshighway, St. Louis, MO 63110.

Received for publication 5 February 1992 and in revised form 30 July 1992.

J. Clin. Invest.

(c) The American Society for Clinical Investigation, Inc.

0021-9738/93/01/0069/08 \$2.00

Volume 91, January 1993, 69-76 which BCG mediates antitumor activity are not clearly understood.

Previous studies have shown that BCG attachment to fibronectin (FN) ${ }^{1}$ in the bladder lumen is required for the development of an antitumor response (6). Inhibition of FN-mediated BCG attachment was shown to inhibit immunization, the expression of delayed type hypersensitivity and antitumor activity (6). Further studies showed that BCG-mediated antitumor activity was dependent on $\mathrm{T}$ lymphocytes (7). These studies led to the hypothesis that BCG-induced antitumor activity is comprised of a series of events that begin with attachment and progress through immune activation and culminate in tumor destruction.

Recent studies demonstrated that BCG attach to and are ingested by bladder epithelial cells ( 8 ). Although the role of cellular attachment and ingestion by epithelial cells in BCGmediated antitumor activity has not been clearly established, this observation suggests that BCG interaction with tumor cells may be associated with immune modulation. Therefore, we initiated studies to better define the interaction of transitional epithelial carcinoma cells with BCG.

The mechanisms of attachment and internalization of microorganisms by cultured nonphagocytic cells has been extensively investigated (9-12). Recently, Isberg and Leong reported that attachment and ingestion of Yersinia pseudotuberculosis by mammalian cells was mediated by integrin receptors (13). This resulted from the direct interaction of a bacterial protein, invasin, with several $\beta_{1}$ integrins. Subsequent reports have confirmed the observation and extended it to other bacteria (14).

The objective of this study was to characterize and evaluate the components involved in BCG attachment and internalization by the bladder tumor cell line T-24. We demonstrate that BCG attachment and ingestion are mediated at least in part by the $\alpha_{5} \beta_{1}$ integrin receptor, and that both processes can be modulated by FN.

\section{Methods}

Bladder tumor cells. The human transitional cell carcinoma cell line T-24 was obtained from American Type Culture Collection (Rockville, MD). The cells were cultured in medium containing Earle's MEM supplemented with $50 \mathrm{U} / \mathrm{ml}$ penicillin, $50 \mathrm{U} / \mathrm{ml}$ streptomycin, $1 \%$ L-glutamine, and 10\% FCS. All tissue culture media and supplements were purchased from Washington University Cancer Center (St. Louis, MO). Tests for mycoplasma were negative.

$B C G$. Pasteur strain (Armand Frappier, Quebec, Canada) at 120 $\mathrm{mg} /$ vial was used. The vaccine was a lyophilized preparation contain-

1. Abbreviations used in this paper: FN, fibronectin; LN, laminin; RITC, rhodamine isothiocyanate; VN, vitronectin. 
ing $10^{7} \mathrm{CFU} / \mathrm{mg}$ dry wt. A $120-\mathrm{mg}$ ampule of BCG was suspended in $10 \mathrm{ml}$ prewarmed RPMI 1640 , and particles representing one or a few bacteria were isolated by a modification of the method reported by Rook and associates (15). The suspension was centrifuged at $3,000 \mathrm{~g}$ for $10 \mathrm{~min}$ at $24^{\circ} \mathrm{C}$. After the medium was removed, BCG were resuspended in $10 \mathrm{ml} \mathrm{RPMI} 1640$ and centrifuged at $250 \mathrm{~g}$ for $3 \mathrm{~min}$ at $24^{\circ} \mathrm{C}$ to eliminate large clumps of bacteria. The top $5 \mathrm{ml}$ of the suspension was removed and used in the attachment and ingestion assay. The number of organisms was determined by measuring the optical density at wave length of $595 \mathrm{~nm}$ and comparing it to a previously established standard curve quantitating CFU from optical densities using the particle isolation technique described above.

Antibodies. Rabbit polyclonal anti-BCG and anti-FN antibodies were purchased from Dako Corp. (Santa Barbara, CA). Rat monoclonal antibodies, B1E5 directed against the $\alpha_{5}$ integrin subunit and AIIB2 directed against the $\beta_{1}$ integrin subunit were provided by Dr. Caroline Damsky, University of California (San Francisco, CA) (16). Murine monoclonal antibody $\mathrm{J} 143$ directed against the $\alpha_{3}$ subunit was a gift from Dr. Lloyd J. Old, Memorial Sloan-Kettering (New York) (17). Rat monoclonal antibody 439-9B directed against the $\beta_{4}$ subunit was a gift from Dr. Stephen Kennel, Oak Ridge National Laboratory (Oak Ridge, TN) (18). Monoclonal antivitronectin antibody was a gift from Dr. David Barnes, Oregon State University (Corvallis, OR) (19). FITC-conjugated goat $\mathrm{F}\left(\mathrm{ab}^{\prime}\right)_{2}$ anti-rabbit IgG and rhodamine isothiocyanate (RITC) conjugated goat $F\left(a b^{\prime}\right)_{2}$ anti-rabbit IgG were obtained from Cappell (Durham, NC).

Extracellular matrix proteins. Human plasma $\mathrm{FN}$ was purified as previously reported (20). Murine laminin (LN) was obtained from Collaborative Research (Bedford, MA). Human vitronectin (VN) was purchased from Telios Pharmaceuticals (San Diego, CA).

Coating latex beads with proteins. Latex beads were coated with proteins by adsorption as described by Cantarero et al. (21). Briefly, beads were washed in 0.1 M PBS, pH 7.0, to remove surfactants. Washed beads were resuspended in PBS containing $200 \mu \mathrm{g} / \mathrm{ml}$ of the
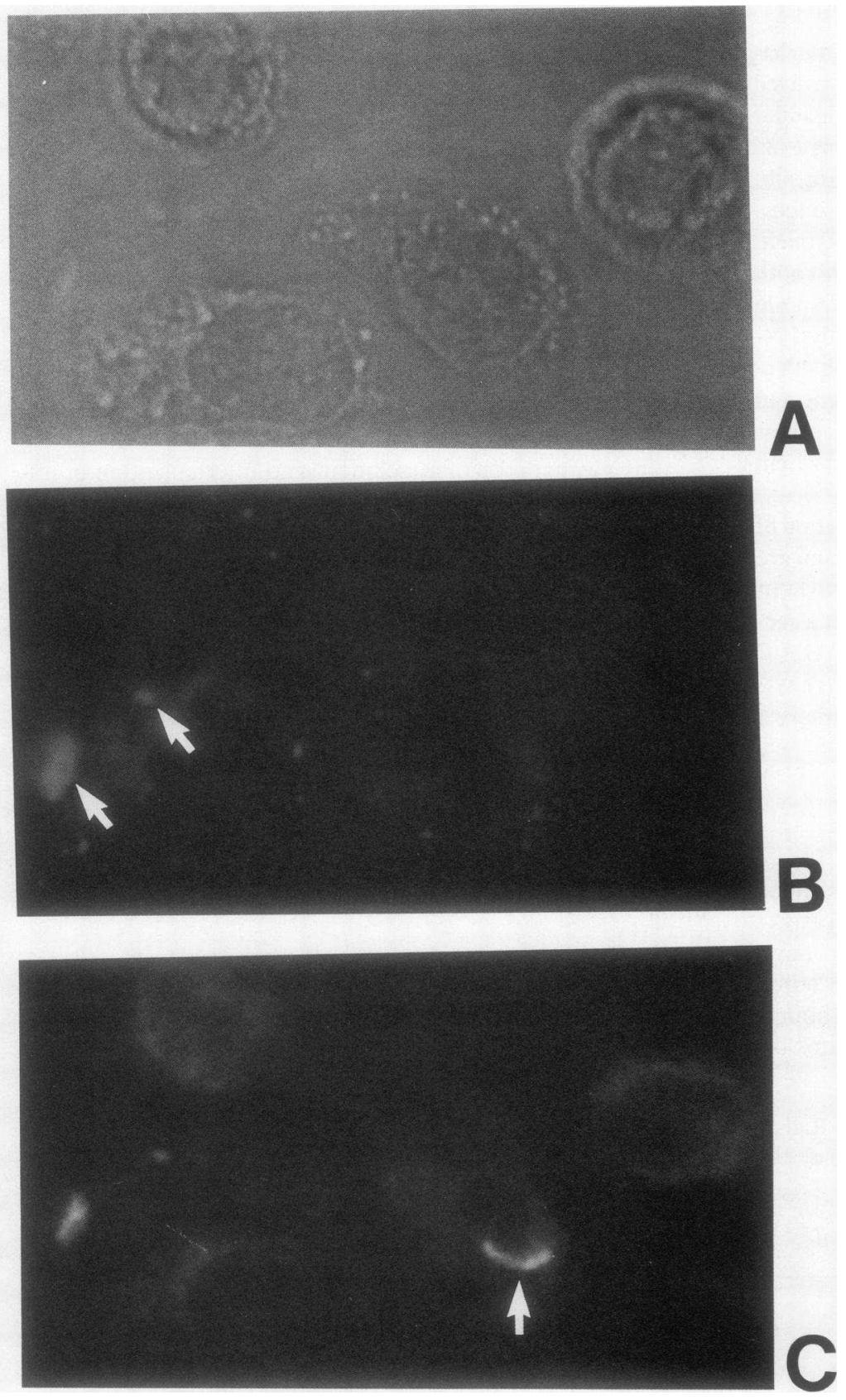

Figure 1. Discrimination between attachment and ingestion using the dual fluorescence assay. $(A)$ Phase contrast. (B) FITC-labeled attached BCG. Attached BCG are indicated by arrows. $(C)$ RITC-labeled ingested BCG, the ingested BCG are indicated by the arrow. Attached BCG also are RITC labeled but are distinguished from ingested bacteria because they also are labeled by FITC ( $\operatorname{see} B)$. 
desired protein and incubated at room temperature overnight. The beads were washed and resuspended in RPMI 1640 supplemented with $0.1 \%$ BSA and $0.05 \%$ sodium azide. Stock preparations were stored at $4^{\circ} \mathrm{C}$. Before use in an ingestions assay, the beads were washed and quantitated on a counter (Coulter Corp., Hialeah, FL) and diluted in RPMI 1640.

$B C G$ ingestion assay. T-24 cells were removed from tissue culture flasks using $10 \mathrm{mM}$ EDTA in PBS, pH 7.2. $10^{5}$ cells in Earle's MEM with the same supplements described above were plated into each well of chamber slides (Lab-Tek 8; Miles Laboratories, Naperville, IL). The cultures were incubated at $37^{\circ} \mathrm{C}$ in $5 \% \mathrm{CO}_{2}$ overnight. Alternatively, T-24 cells were plated in Lab-Tek chambers precoated overnight with FN, LN, or VN as previously described (22). Cells were allowed to attach for $2 \mathrm{~h}$. Attached cells were washed twice with prewarmed PBS, and $10^{5} \mathrm{CFU} B C G$ were added into each chamber containing adherent $\mathrm{T}-24$ cells. The cultures were incubated at $37^{\circ} \mathrm{C}$ in $5 \% \mathrm{CO}_{2}$ for $3 \mathrm{~h}$ to allow BCG internalization.

Attachment and ingestion were assessed by a modification of the double immunofluorescence assay described by Portnoy et al. (23). After washing, $10 \%$ horse serum in PBS was added for 30 min to block nonspecific antibody binding. Blocking was followed by the addition of a 1:100 dilution of polyclonal rabbit anti-BCG antibody for $30 \mathrm{~min}$. After washing, 1:200 dilution of FITC-conjugated goat anti-rabbit IgG was added for $30 \mathrm{~min}$ to stain extracellular BCG. After washing, methanol was added for 5 min to permeablize the T-24 cells. Subsequently, both extracellular and intracellular BCG were stained with RITC by adding anti-BCG antibody followed by 1:200 dilution of RITC-conjugated goat anti-rabbit IgG as described for the FITC antibody. After washing, slides were mounted in a solution containing $50 \%$ glycerol and $0.1 \% p$-phenylenediamine (Sigma Chemical Company, St. Louis,
MO) in PBS. All staining procedures were carried out at room temperature, and all antibodies were diluted with $10 \%$ horse serum in PBS. A representative photograph demonstrating attached (stained with both FITC and RITC) and ingested (stained with RITC only) bacteria is provided in Fig. 1. An electron micrograph demonstrating both attachment and ingestion is shown in Fig. 2.

Assessment of BCG attachment and ingestion by T-24 cells. In each experiment, a total of 100 cells were counted at a magnification of 1,000. Attachment and ingestion rates are expressed as the percentage of cells that had extracellular and/or intracellular BCG among the total of 100 cells counted. If cells had both extracellular and intracellular BCG, they were scored as ingesting cells. All experiments were repeated three times on separate days. All data values are presented as mean \pm SEM of three independent determinations. Statistical analysis was performed using the Student's paired $t$ test.

Inhibition studies. BCG were incubated with anti-BCG antibody or $\mathrm{T}-24$ cells were incubated with each anti-integrin receptor antibody at $37^{\circ} \mathrm{C}$ in $5 \% \mathrm{CO}_{2}$ for $30 \mathrm{~min}$, after which the $\mathrm{BCG}$ ingestion assay was performed. Antibodies were diluted with RPMI 1640. As a control, BCG or T-24 cells were incubated with medium only.

Anti- $\beta_{1}$ antibodies block attachment of T-24 cells to both FN and LN, while anti- $\alpha_{5}$ blocks attachment to only FN. To eliminate the influence of these antibodies on cellular attachment, FN-, VN-, or LNcoated plates were used as dictated by the experiment. T-24 cells attached and spread equally well on all three proteins (data not shown). Neither LN nor VN affected BCG attachment or ingestion to T-24 cells.

Electron microscopy. The ingestion assay was performed as described above. Electron microscopy was performed as previously described (8). Briefly, cells were fixed in $1 \%$ glutaraldehyde in HBSS and
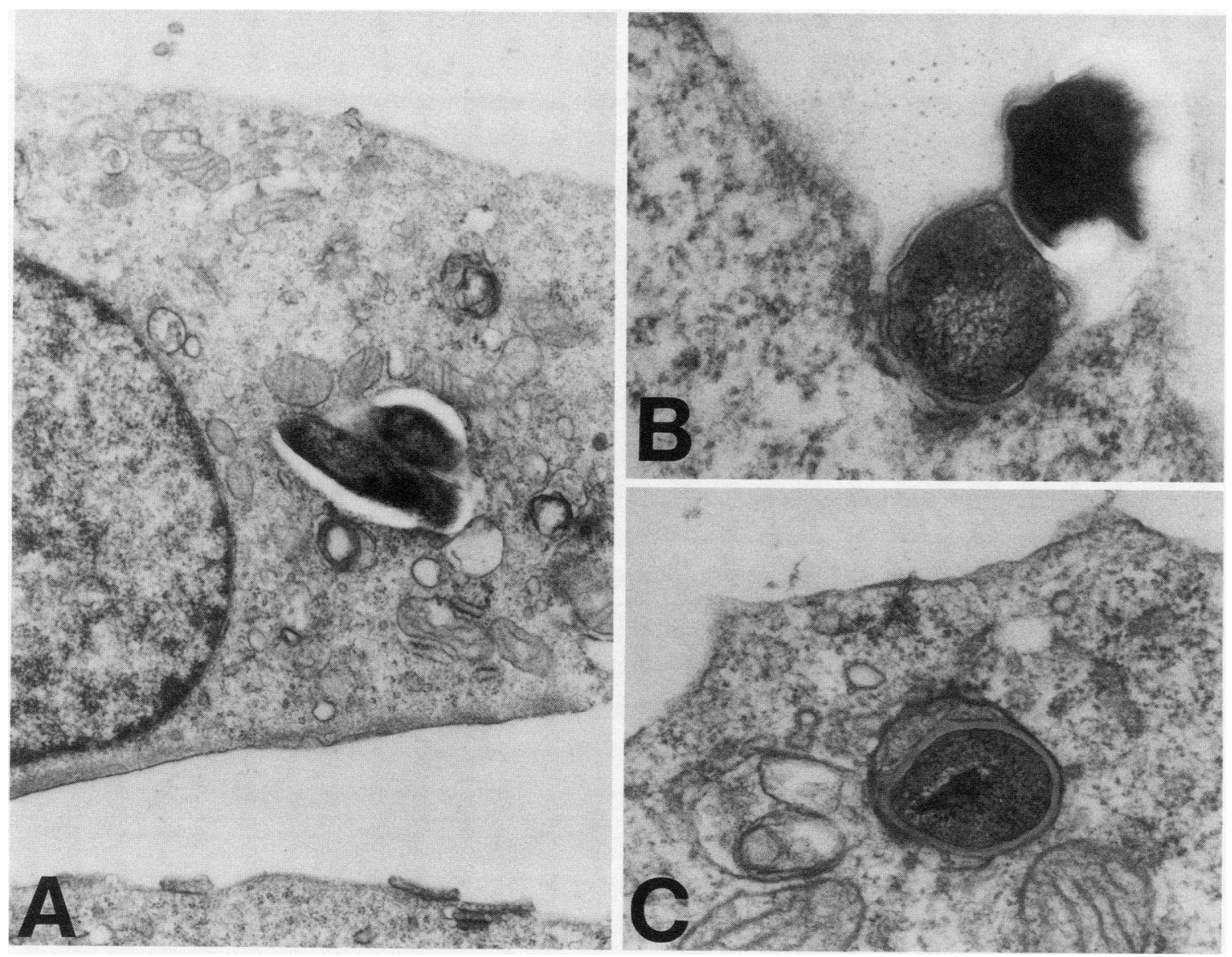

Figure 2. Electron micrograph demonstrating BCG attachment and ingestion by T-24 cells. $(A) \times 23,000 ;(B) \times 90,000 ;(C) \times 59,000$. 


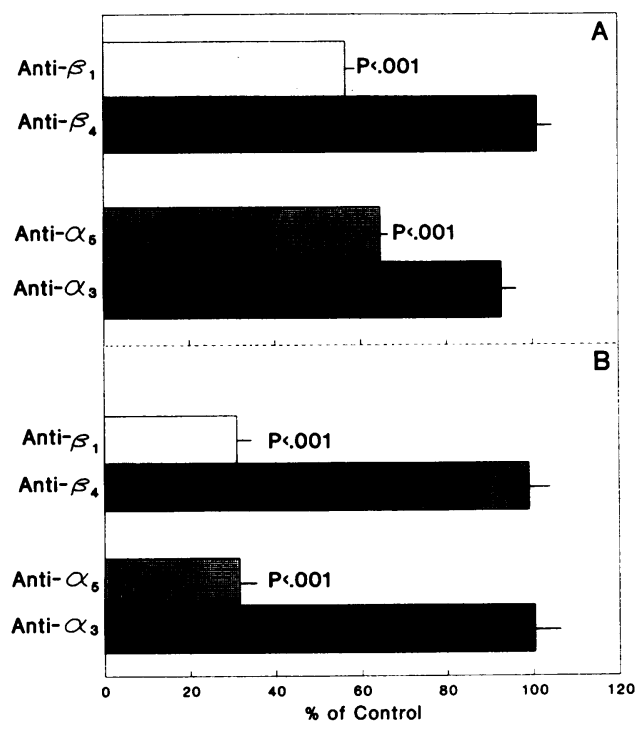

Figure 3. Effect of anti-integrin antibodies on the attachment and ingestion of BCG by T-24 cells. $(A)$ Attachment. $(B)$ Ingestion. The antibody concentrations were 1:10 dilutions of the preparations provided by the respective investigators (see Methods) and were determined to provide maximal inhibitory activity.

postfixed in $1 \% \mathrm{OsO}_{4}$. The preparation was dehydrated through a series of acetone baths and embedded in Spurr resin. Sections were cut and stained in $1 \%$ uranyl acetate and Reynold's lead.

\section{Results}

Effect of Anti-integrin receptor antibodies on BCG attachment and ingestion by T-24 cells. Previous studies demonstrated that transitional epithelial cells, including the T-24 bladder tumor cell line, ingested BCG (8). Since previous reports demonstrated a role for integrin receptors in the ingestion of some bacteria by nonphagocytic cells (13), we evaluated the role of integrins in BCG attachment and ingestion. Flow cytometric analysis and immunoprecipitation studies of T-24 cells demon- strated the expression of $\alpha_{2}, \alpha_{3}, \alpha_{5}, \alpha_{6}, \alpha_{\mathrm{v}}, \beta_{1}, \beta_{3}$, and $\beta_{4}$ integrin subunits and an absence of $\alpha_{4}$ (unpublished data). The role of these integrin components in BCG internalization was evaluated with monoclonal antibodies directed against specific integrin chains. The antibodies to $\beta_{1}, \alpha_{3}$, and $\alpha_{5}$ have been shown to block cellular attachment to extracellular matrix proteins, while the anti- $\beta_{4}$ is not a functionally inhibitory antibody $(16-18,24)$. T-24 cells were pretreated with each antibody, after which attachment and ingestion were quantitated. Inhibition of BCG attachment was observed for anti- $\beta_{1}$ and anti- $\alpha_{5}$ but not for anti- $\beta_{4}$ or anti- $\alpha_{3}$ antibodies (Fig. $3 A$ ). An even greater decrease in BCG ingestion was observed for anti- $\beta_{1}$ and anti- $\alpha_{5}$ (Fig. $3 B$ ). Table I (Experiment 1 ) contains raw data from a representative experiment demonstrating the effects of anti-integrins on attachment and ingestion. The inhibitory effect of these antibodies was dose dependent with a maximum inhibition at a 1:10 dilution of culture supernatant (data not shown).

Role of extracellular matrix proteins in BCG attachment and ingestion by T-24 cells. The integrin subunits $\alpha_{5}$ and $\beta_{1}$ together comprise the classical FN receptor (25-26), and T-24 have been demonstrated to attach to $\mathrm{FN}$ via this receptor (22). The antibody data suggest that the $\alpha_{5} \beta_{1}$ receptor is an important receptor for BCG attachment and ingestion. Since previous studies showed that BCG bind specifically to FN by a bacterial surface receptor $(27,28)$, we investigated whether FN acts as an opsonin in BCG attachment and internalization. LN, which does not bind to BCG but mediates attachment and spreading of T-24 cells, was also tested (29). The addition of either soluble human plasma FN or murine $\mathrm{LN}$ had no effect on BCG attachment and ingestion (data not shown). This observation is consistent with our previous studies, which demonstrated that physiologic salt concentrations inhibited the binding of soluble plasma FN to BCG (29). In contrast, precoating slides with $\mathrm{FN}$ augmented attachment and ingestion in a dosedependent manner (Fig. 4). The highest concentration of FN $(100 \mu \mathrm{g} /$ well $)$ increased BCG attachment by $91.8 \%(P<0.01)$ and ingestion by $82.3 \%(P<0.001)$. $\mathrm{LN}$ had no effect on either attachment or ingestion. T-24 attachment and spreading was indistinguishable on LN- and FN-coated surfaces. However,

Table I. Effect of Modulating Agents on BCG Attachment and Ingestion by T-24 Cells

\begin{tabular}{|c|c|c|c|c|c|c|c|c|c|c|c|c|c|}
\hline & \multirow{3}{*}{$\begin{array}{l}\text { No. of bacteria } \\
\text { per cell }\end{array}$} & \multicolumn{5}{|c|}{$\begin{array}{c}\text { Experiment } 1 \\
\text { (summarized in Fig. 3) }\end{array}$} & \multicolumn{3}{|c|}{$\begin{array}{c}\text { Experiment } 2 \\
\text { (summarized in Fig. 5) }\end{array}$} & \multicolumn{2}{|c|}{$\begin{array}{c}\text { Experiment } 3 \\
\text { (summarized in Fig. 10) }\end{array}$} & \multicolumn{2}{|c|}{$\begin{array}{c}\text { Experiment } 4 \\
\text { (summarized } \\
\text { in Fig. 7) }\end{array}$} \\
\hline & & \multirow[b]{2}{*}{ Control } & \multicolumn{3}{|c|}{ Anti-integrins* } & \multirow[b]{2}{*}{$\alpha_{s}$} & \multicolumn{3}{|c|}{ Anti-ECM ${ }^{\ddagger}$} & \multicolumn{2}{|c|}{ Anti-BCG FN Receptors } & \multicolumn{2}{|c|}{$\begin{array}{l}\text { Opsonized } \\
\text { BCG }^{I I}\end{array}$} \\
\hline & & & $\beta_{4}$ & $\beta_{1}$ & $\alpha_{3}$ & & Control & VN & FN & Control & Anti-p55 & BSA & FN \\
\hline Attached, uningested & $1-2$ & 17 & 15 & 8 & 22 & 14 & 16 & 15 & 2 & 17 & 10 & 14 & 5 \\
\hline \multirow[t]{2}{*}{$\mathrm{BCG}$} & $3-5$ & 3 & 4 & 2 & 2 & 1 & 1 & 1 & 0 & 20 & 1 & 1 & 12 \\
\hline & $>5$ & 0 & 2 & 1 & 0 & 0 & 3 & 2 & 0 & 7 & 0 & 0 & 10 \\
\hline Ingested & $1-2$ & 10 & 10 & 4 & 8 & 4 & 7 & 6 & 1 & 9 & 1 & 5 & 2 \\
\hline \multirow[t]{2}{*}{ BCG } & $3-5$ & 1 & 3 & 0 & 2 & 0 & 1 & 3 & 0 & 6 & 0 & 1 & 14 \\
\hline & $>5$ & 1 & 0 & 0 & 2 & 0 & 2 & 3 & 0 & 8 & 0 & 1 & 3 \\
\hline
\end{tabular}

The table contains representative experiments from each of four separate studies that are summarized in Figs. 3, 5, 7, and 10. The data are reported as the number of cells in each respective category per 100 total cells.

* Antibody concentration, 1:10 dilution of culture supernatant.

₹ ECM, extra cellular matrix protein; antibody concentration, $2.5 \mu \mathrm{g} / \mathrm{ml}$.

$\S$ Antibody concentration, 1:5 dilution of culture supernatant; assay performed on FN-coated surfaces.

" BCG precoated with FN as described in Methods. 


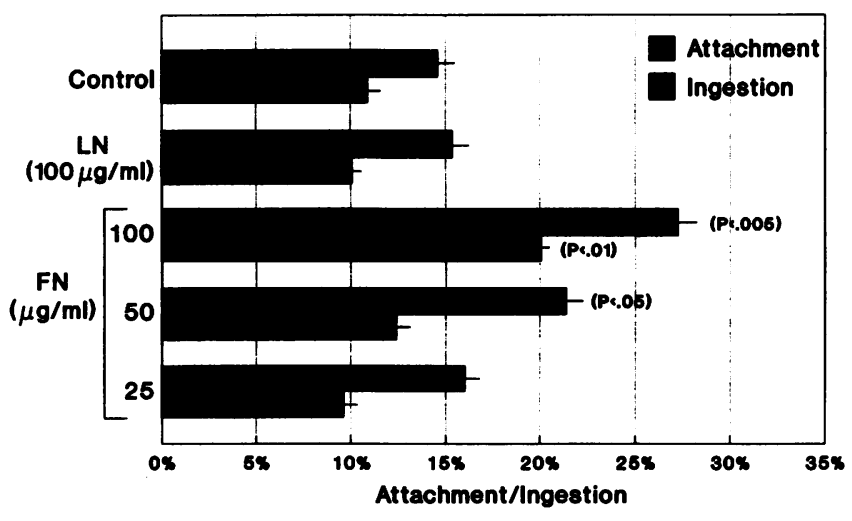

Figure 4. Effect of FN on the attachment and ingestion of BCG by T-24 cells. Surfaces were precoated with the indicated concentration of each protein as described in Methods.

T-24 attachment and spreading on FN was maximal at a coating concentration of $10 \mu \mathrm{g} / \mathrm{ml}$, which had no effect on BCG attachment. This suggested that the increased attachment and ingestion of BCG by T-24 on surfaces coated with high concentrations of FN resulted from BCG interaction with the adherent FN. The concentration of FN that induced maximal BCG attachment to FN-coated surfaces is consistent with this interpretation $(27,28)$. These observations were equivalent for T-24 cells plated on FN for either $2 \mathrm{~h}$ or overnight before the ingestion assay. All remaining experiments were performed using 2-h adherence to surfaces coated with $100 \mu \mathrm{g} / \mathrm{ml}$ of $\mathrm{LN}$ or FN.

Further studies were performed to determine the effect of anti-FN antibody on attachment and ingestion by T-24 cells plated on LN-coated surfaces. Purified rabbit polyclonal antiFN inhibited attachment and ingestion by $91 \%$ and $88 \%$, respectively (Fig. 5 and Table I, Experiment 2). Inhibition by anti-FN was concentration dependent. No inhibition was observed using antibodies directed against vitronectin, which did not affect cell attachment or spreading on either FN or LN. Further studies were performed with an mAb, HFN 7.1, which is known to block cell attachment to the RGD site on FN but not FN attachment to BCG (30). When T-24 cells were plated on LN, HFN 7.1 inhibited attachment and ingestion of BCG up to 60 and 70\%, respectively (Fig. 6). Finally, pretreatment of BCG with FN under conditions which allow FN binding to

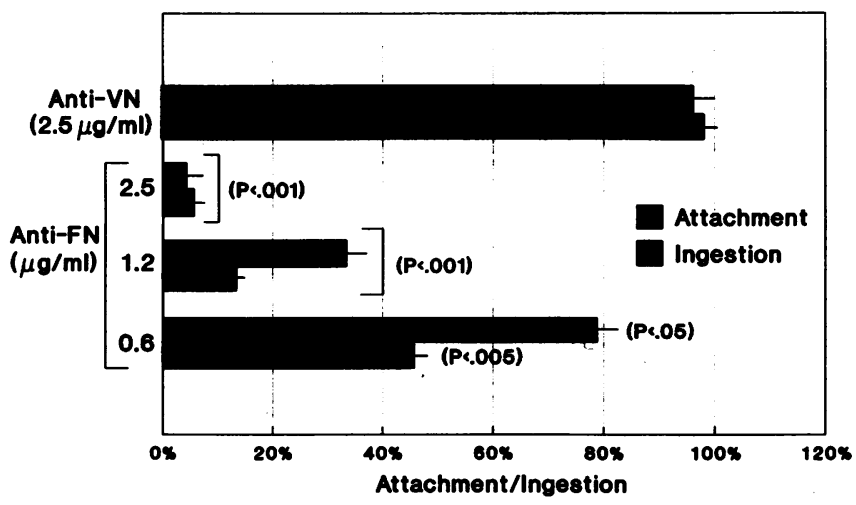

Figure 5. Effect of polyclonal rabbit anti-FN on BCG attachment and ingestion by $\mathrm{T}-24$ cells.

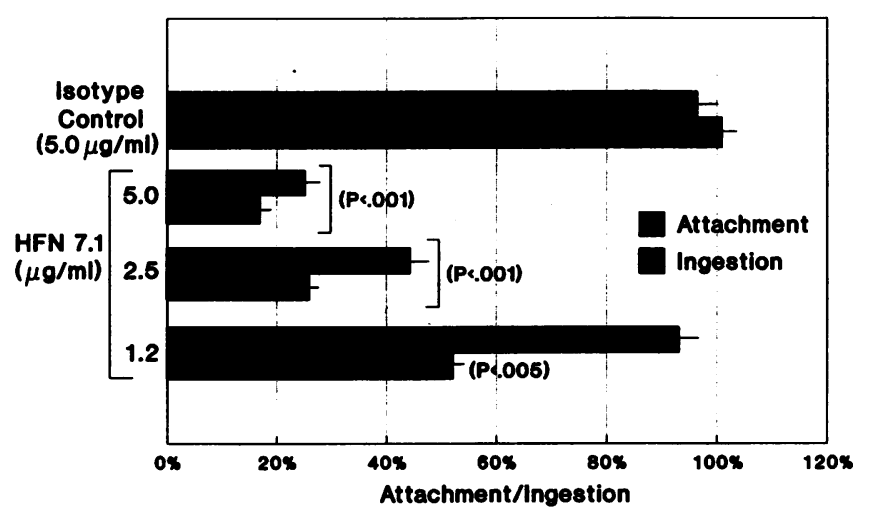

Figure 6. Effect of monoclonal anti-FN, which inhibits cellular binding to the RGD cell binding site, on BCG attachment and ingestion by $\mathrm{T}-24$ cells.

BCG augmented attachment and ingestion by T- 24 cells ( Fig. 7 and Table I, Experiment 4). These data show that FN can opsonize BCG, and that such opsonization enhances both BCG attachment and ingestion by T-24 cells on both a percentage basis and as a function of the number of bacteria associated with the cells.

Since our data show that BCG attach to FN at a site distinct from the RGD cell binding site (data not shown), the potential for an opsonic role for FN was further investigated. Initially, polystyrene beads ( $3 \mu \mathrm{m}$ ) were coated with either FN, $L N$, or BSA, and attachment and ingestion of these beads were assessed using T-24 cells plated on VN. Both FN- and LN-coated beads attached and were ingested by T-24 cells, while BSAcoated beads were not ingested (data not shown). Further studies were performed to determine the effect of antibodies to the $\alpha_{5}$ and $\beta_{1}$ integrin subunits on ingestion. Both anti- $\alpha_{5}$ and anti$\beta_{1}$ inhibited the ingestion of FN-coated beads, while only anti$\beta_{1}$ inhibited the ingestion of LN-coated beads (Fig. 8).

Competition experiments were performed in which either $\mathrm{LN}$ - or FN-coated beads were coincubated with BCG in the ingestion assay. FN-coated beads but not $\mathrm{LN}$-coated beads inhibited BCG attachment and ingestion, suggesting competition for the same T-24 receptor (Fig. 9).

Effect of antibodies to BCG surface components on attachment and ingestion. To further explore the necessity for FN binding by BCG in attachment and ingestion by T-24, we evaluated the BCG surface structures required for recognition. Poly-

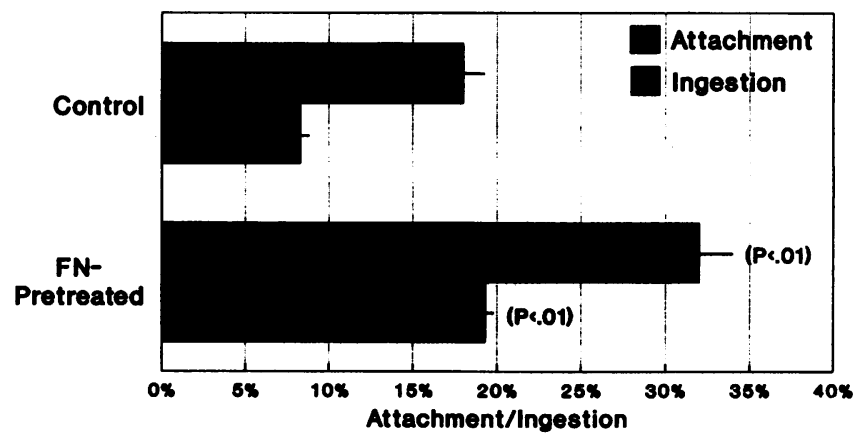

Figure 7. Effect of FN pretreatment of BCG on attachment and ingestion by $\mathrm{T}-24$ cells. 


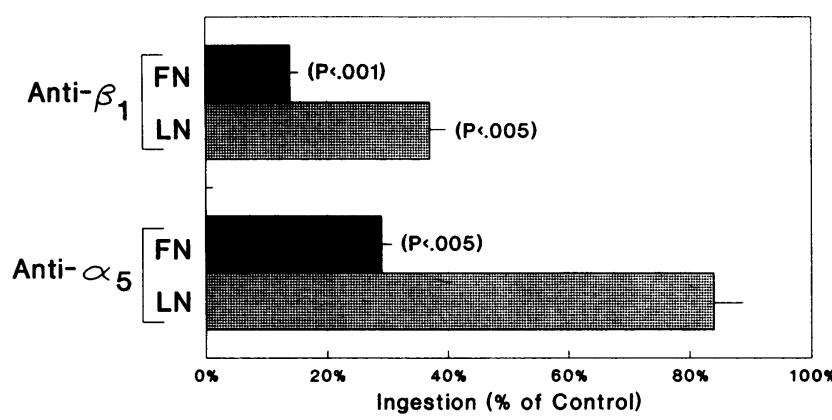

Figure 8. Effect of anti-integrin antibodies on the ingestion of latex beads coated with either FN or LN. Antibody concentration, 1:10 dilution of cultured supernatant.

clonal anti-BCG completely inhibited both attachment and ingestion, demonstrating that a specific interaction was required (data not shown). Importantly, an $\mathrm{mAb}$ that recognizes the BCG 55-kD FN receptor (anti-p55) and prevents BCG attachment to FN (Ratliff, T. L., R. J. McCarthy, and E. J. Brown, manuscript submitted for publication) also inhibited BCG attachment and ingestion (Fig. 10). These data demonstrate that this bacterial receptor is necessary for BCG attachment to T-24 cells, and are consistent with the hypothesis that FN mediates binding of BCG to this transitional epithelial cell line.

\section{Discussion}

The binding of BCG to FN is a necessary step in the development of an antitumor response after the intravesical instillation of BCG for bladder cancer (6). Our studies demonstrated that only when BCG attached to FN was it retained with an avidity sufficient to induce an antitumor response. In vitro and in vivo studies showed that BCG were ingested by bladder tumor cells leading to the hypothesis that internalization was a secondary step that occurred after BCG attachment to FN (8). In our studies to dissect the mechanisms of internalization of BCG by the tumor cells, we have discovered an additional unexpected role for FN. In addition to its role in retention of the BCG in the bladder, FN acts as a critical signal for binding and internalization of BCG by the epithelial tumor cells.

The role of FN in attachment and ingestion appears to be opsonic. This hypothesis is supported by data from several experiments. First, the preopsonization of BCG by FN markedly

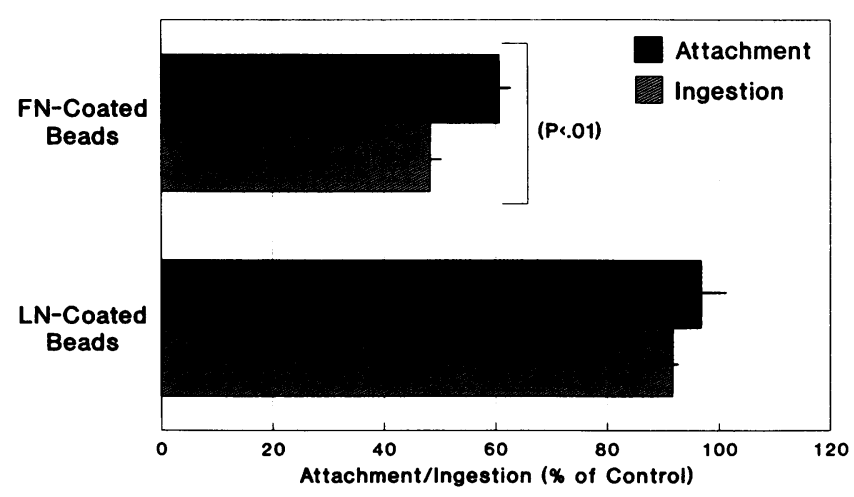

Figure 9. Effect of FN-coated beads on the attachment and ingestion of BCG by T-24 cells.

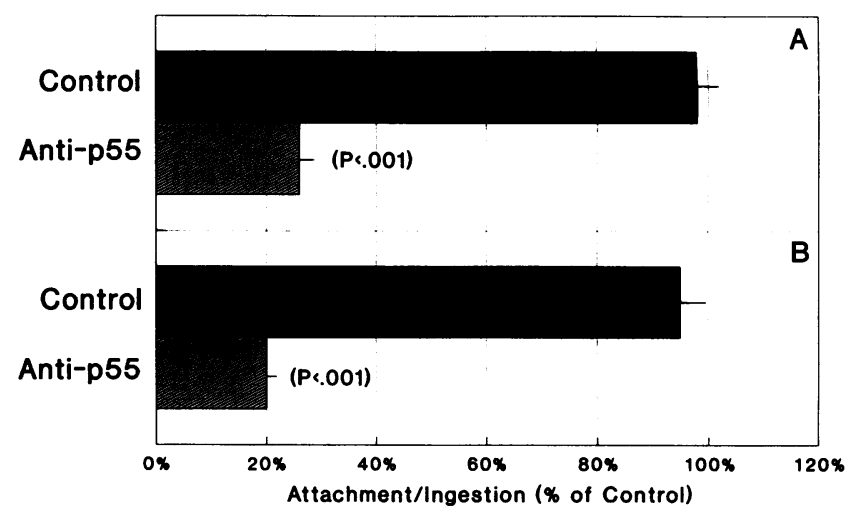

Figure 10. Effect of mAb to the BCG FN receptor (anti-p55) on BCG attachment $(A)$ and ingestion $(B)$ by T-24 cells.

enhances both attachment and ingestion. Not only was the percentage of cells ingesting BCG increased, but there also was a marked increase in the number of bacteria ingested by each cell. Furthermore, FN-coated latex beads but not LN-coated beads competed with BCG for attachment and ingestion sites. Finally, an mAb to a BCG FN binding protein blocked both attachment and ingestion. While an opsonic role for $\mathrm{FN}$ has been reported for other bacterial species, opsonization in these reports resulted in attachment but did not initiate ingestion $(33,34)$. In our studies, FN opsonization of BCG also initiated ingestion.

An alternative hypothesis is $\mathrm{FN}$ induced modulation of a distinct receptor. Previous studies demonstrated that FN upregulates complement and $\mathrm{Fc}$ receptors $(31,32)$; however, these receptors are not expressed on T-24 cells (unpublished observation). The modulation of unknown phagocytic receptors for BCG cannot be definitively excluded, although all our data are supportive of a direct opsonic role for FN.

Previous studies have evaluated the effect of FN on bacterial attachment and phagocytosis by macrophages, neutrophils, and endothelial cells (33-35). These studies have uniformly shown FN to mediate attachment but not to initiate ingestion. van de Water et al. (34) showed that the phagocytosis of Staphylococcus aureus and Salmonella typhimurium by several phagocytic cell types was independent of FN. These observations were supported by Proctor and associates (35) who showed FN-mediated attachment but not ingestion of $S$. aureus by human neutrophils. Hamill et al. (33) investigated the effects of FN on $S$. aureus ingestion by cultured bovine aortic endothelial cells. These investigators observed an FN-induced increase in the attachment of $S$. aureus to the endothelial cells, but FN had no effect on phagocytosis.

In a review of bacterial attachment mechanisms, Isberg (13) suggested that the primary function of bacterial attachment to extracellular matrix proteins was colonization, while the initiation of ingestion required direct attachment of bacteria to integrin receptors. This hypothesis was supported by studies on Y. pseudotuberculosis invasion of mammalian epithelial cell lines (14). In these studies, the protein invasin, which is known to be sufficient for inducing attachment and ingestion by traditionally nonphagocytic cells, was shown to attach to $\beta_{1}$ integrin receptors. Similar results were reported for Bordetella pertussis (14). Our results also demonstrate bacterial attachment to an epithelial cell $\beta_{1}$ integrin receptor, the $\alpha_{5} \beta_{1}$ FN 
receptor; however, the attachment mechanism differs from those previously reported for other bacteria, since FN opsonization of BCG is required. In addition BCG attachment via the FN bridge initiated ingestion by this epithelial cell line.

The attachment and ingestion of mycobacteria to traditionally nonphagocytic cells is well established. The phenomenon is best characterized for Mycobacterium leprae in which phagocytosis has been documented for muscle cells, neurons, endothelial cells, fibroblasts and Schwann cells (37-39). While ingestion is best characterized for $M$. leprae, it has been observed for Mycobacterium tuberculosis, BCG, Mycobacterium fortuitum, Mycobacterium ulcerans, and Mycobacterium balnei (40). The in vivo importance of this phenomenon is not clear, but previous investigators suggested that Schwann cells may be a primary and persistent source of $M$. leprae (41). Several other mycobacterial species attach to epithelial cells and are ingested via $\beta_{1}$ integrin receptors as is described for BCG; all require FN opsonization (submitted for publication). These data suggest that mycobacterial uptake into epithelial cells via FN opsonization is a uniform phenomenon for this bacterial genus. Preliminary data suggest that this mechanism also is operative in macrophages, the more traditional residence of invasive mycobacteria. These data also suggest that a reexamination of the role of epithelial cell invasion in mycobacterial pathogenesis is in order. While little attention has been focused on this aspect of infection, it is clear that mycobacteria invading through the gut or the respiratory tract need to cross an epithelial border before systemic invasion is possible.

The mechanism(s) by which BCG mediates antitumor activity have not been defined. Based on our current and past studies, we hypothesize that FN attachment to the mycobacterial FN receptor plays a key role in this process. Not only does this receptor mediate retention of BCG at tumor sites (6), but it also plays a critical role in uptake by the epithelial tumors themselves. Presumably, uptake is followed by lysosomal degradation and antigen presentation to the immune system. If this hypothesis is correct, the mycobacterial FN receptor, apparently well conserved through the genus, may play a critical role in initiation of the antitumor response.

\section{Acknowledgments}

The authors gratefully acknowledge Dr. Caroline Damsky, Dr. Lloyd J. Old, Dr. Stephen Kennel, and Dr. David Barnes for providing reagents, and Regina Wigger for her secretarial expertise.

This work was supported by grants CA42487, CA37926, and CA44426 to T. L. Ratliff from the National Cancer Institute and partially supported by a National Kidney Foundation Fellowship to W. B. Telle.

\section{References}

1. Morales, A., D. Eidinger, and A. W. Bruce. 1976. Intracavitary bacillus Calmette-Guerin in the treatment of superficial bladder tumors. J. Urol. 116:180-183.

2. Herr, H. W., C. M. Pinsky, W. F. Whitmore, Jr., H. F. Oettgen, and M. R. Melamed. 1983. Effect of intravesical bacillus Calmette-Guerin (BCG) on carcinoma in situ of the bladder. Cancer (Phila.). 51:1323-1326.

3. Brosman, S. A. 1982. Experience with bacillus Calmette-Guerin in patients with superficial bladder carcinoma. J. Urol. 128:27-30.

4. Mori, K., D. L. Lamm, and E. D. Crawford. 1986. A trial of bacillus
Calmette-Guerin versus Adriamycin in superficial bladder cancer: a south-west oncology group study. Urol. Int. 41:254-259.

5. Lamm, D. L., B. A. Blumenstein, E. D. Crawford, J. E. Montie, P. Scardino, H. G. Grossman, T. H. Stanisic, J. A. Smith, Jr., J. Sullivan, M. F. Sarosdy, et al. 1991. A randomized trial of intravesical doxorubicin and immunotherapy with bacille Calmette-Guerin for transitional-cell carcinoma of the bladder. $N$. Engl. J. Med. 325:1205-1209.

6. Kavoussi, L. R., E. J. Brown, J. K. Ritchey, and T. L. Ratliff. 1990. Fibronectin-mediated Calmette-Guerin bacillus attachment to murine bladder mucosa. J. Clin. Invest. 85:62-67.

7. Ratliff, T. L., D. P. Gillen, and W. J. Catalona. 1986. Requirement of a thymus dependent immune response for BCG-mediated antitumor acticity. $J$. Urol. 137:155-158.

8. Becich, M. J., S. Carroll, and T. L. Ratliff. 1991. Internalization of bacille Calmette-Guerin by bladder tumor cells. J. Urol. 145:1316-1324.

9. Saito, H., H. Tomioka, T. Watanabe, and K. Sato. 1986. Mechanisms of phagocytosis of Mycobacterium leprae and other mycobacteria by human oligodendroglial cells. Infect. Immun. 51:163-167.

10. Band, A. H., S. D. Chitamber, A. Bhattacharya, and G. P. Talwar. 1986. Mechanism of phagocytosis of mycobacteria by Schwann cells and their comparison with macrophages. Int. J. Lepr. 54:294-299.

11. Hamill, R. J., J. M. Vann, and R. A. Procter. 1986. Phagocytosis of Staphylococcus aureus by cultured bovine aortic endothelial cells: model for postadherence events in endovascular infections. Infect. Immun. 54:833-836.

12. Mukherjee, R., and N. H. Antia. 1986. Host-parasite interrelationship between $M$. leprae and Schwann cells in vitro. Int. J. Lepr. 54:632-638.

13. Isberg, R. R., and J. M. Leong. 1990. Multiple $\beta_{1}$ chain integrins are receptors for invasin, a protein that promotes bacterial penetration into mammalian cells. Cell. 60:861-871.

14. Leininger, E., M. Roberts, J. G. Kenimer, I. G. Charles, N. Fairwesther, P. Novotny, and M. J. Brennan. 1991. Pertactin, an Aru-Gly-Asp-containing Bordetella pertussis surface protein that promotes adherence of mammalian cells. Proc. Natl. Acad. Sci. USA. 88:345-349.

15. Rook, G. A. W., J. Steele, A. M. Varey, and J. L. Stanford. 1985. I-A restricted activation by $\mathrm{T}$ cell lines of anti-tuberculosis activity in murine macrophages. Clin. Exp. Immunol. 59:414-420.

16. Hall, D. E., L. F. Reichardt, E. Crowley, B. Holley, H. Moezzi, A. Sonnenberg, and C. H. Damsky. 1990. The $\alpha_{1} / \beta_{1}$ and $\alpha_{6} / \beta_{1}$ integrin heterodimers mediate cell attachment to distinct sites on laminin. J. Cell Biol. 110:2175-2184.

17. Fradet, Y., C. Cordon-Cardo, W. F. Whitmore, Jr., M. R. Melamed, and L. J. Old. 1986. Cell surface antigens of human bladder tumors: definition of tumor subsets by monoclonal antibodies and correlation with growth characteristics. Cancer Res. 46:5183-5188.

18. Kennel, S. J., L. J. Foote, R. Falcioni, A. Sonnenberg, C. D. Stringer, C. Crouse, and M. E. Hemler. 1989. Analysis of the tumor-associated antigen TSP180. J. Biol. Chem. 264:15515-15521.

19. Basara, M. L., J. B. McCarthy, D. W. Barnes, and L. T. Furcht. 1985. Stimulation of haptotaxis and migration of tumor cells by serum spreading factor. Cancer Res. 45:2487-2494.

20. Pommier, C. G., S. Inada, L. F. Fries, T. Takahashi, M. M. Frank, and E. J. Brown. 1983. Plasma fibronectin enhances phagocytosis of opsonized particles by human peripheral blood monocytes. J. Exp. Med. 157:1844-1854.

21. Cantarero, L. E., J. E. Butler, and J. W. Osborne. 1980. The absorptive characteristics of proteins for polystyrene and their significance in solid-phase immunoassays. Anal. Biochem. 105:375-382.

22. Coplen, D. E., E. J. Brown, J. McGarr, and T. L. Ratliff. 1991. Characterization of fibronectin attachment by a human transitional cell carcinoma line, T-24. J. Urol. 145:1312-1315.

23. Portnoy, D. A., P. S. Jaks, and D. J. Hinrichs. 1988. Role of hemolysin for the intracellular growth of Listeria monocytogenes. J. Exp. Med. 167:1459-1471.

24. Staquet, M. J., B. Levarlet, C. Dezutter-Dambuyant, D. Schmitt, and J. Thivolet. 1990. Identification of specific human epithelial cell integrin receptors as VLA proteins. Exp. Cell Res. 187:277-283.

25. Takada, Y., C. Huang, and M. E. Hemler. 1987. Fibronectin receptor structures in the VLA family of heterodimers. Nature (Lond.). 326:607-609.

26. Rouslahti, E. 1988. Fibronectin and its receptors. Annu. Rev. Biochem. 57:375-413.

27. Ratliff, T. L., J. O. Palmer, J. A. McGarr, and E. J. Brown. 1987. Intravesical bacillus Calmette-Guerin therapy for murine bladder tumors: initiation of the response by fibronectin-mediated attachment of bacillus Calmette-Guerin. Cancer Res. 47:1762-1766.

28. Ratliff, T. L., L. R. Kavoussi, and W. J. Catalona. 1988. Role of fibronectin in intravesical BCG therapy for superficial bladder cancer. J. Urol. 139:410414.

29. Aslanzadeh, J., E. J. Brown, S. P. Quillin, J. K. Ritchey, and T. L. Ratliff. 1989. Characterization of soluble fibronectin binding to bacille Calmette-Guerin. J. Gen. Microbiol. 135:2735-2741.

30. Bohnsack, J. F., T. Takahashi, and E. J. Brown. 1986. Interaction of 
culture-derived macrophages with the fibroblast-binding domain of fibronectin is a necessary but inefficient signal for fibronectin enhancement of CR1-mediated phagocytosis. J. Immunol. 136:3793-3798.

31. Bohnsack, J. F., J. J. O’Shea, T. Takahashi, and E. J. Brown. 1984. Fibronectin-enhanced phagocytosis of an alternative pathway activator by human culture-derived macrophages is mediated by the $\mathrm{C} 4 \mathrm{~B} / \mathrm{C} 3 \mathrm{~b}$ complement receptor (CR1). J. Urol. 135:2680-2686.

32. Bevilacqua, M. P., D. Amrani, M. W. Mosesson, and C. Bianco. 1981. Receptors for cold-insoluble flobulin (plasma fibronectin) on human monocytes. J. Exp. Med. 153:42-60.

33. Hamill, R. J., J. M. Vann, and R. A. Proctor. 1986. Phagocytosis of Staphylococcus aureus by cultured bovine aortic endothelial cells: model for postadherence events in endovascular infections. Infect. Immun. 54:833-836.

34. van de Water, L., A. T. Destree, and R. O. Hynes. 1983. Fibronectin binds to some bacteria but does not promote their uptake by phagocytic cells. Science (Wash. DC). 220:201-204.

35. Proctor, R. A., E. Prendergast, and D. F. Mosher. 1982. Fibronectin medi- ates attachment of Staphylococcus aureus to human neutrophils. Blood. 59:681687.

36. Isberg, R. R. 1991. Discrimination between intracellular uptake and surface adhesion of bacterial pathogens. Science (Wash. DC). 252:934-938.

37. Band, A. H., S. D. Chitamber, A. Bhattacharya, and G. P. Talwar. 1986. Mechanism of phagocytosis of mycobacteria by Schwann cells and their comparison with macrophages. Int. J. Lepr. 54:294-299.

38. Cornette, J., A. Caprin, and M. A. Quaissi. 1988. Trypanosoma cruzi: fibronectin promotes uptake of epimastigote culture forms by human neutrophils and monocytes. Int. Arch. Allergy Appl. Immunol. 86:139-146.

39. Griffin, F. M., J. A. Griffin, J. E. Leider, and S. C. Silverstein. 1975. Studies on the mechanism of phagocytosis. I. Requirements for circumferential attachment of particle-bound ligans to specific receptors on the macrophage plasma membrane. J. Exp. Med. 142:1263-1282.

40. Shepard, C. C. 1957. A comparison of the growth of selected Mycobacteria in HeLa, monkey kidney, and human amonion cells in tissue culture. J. Exp. Med. 105:237-245.

41. Stoner, G. L. 1979. Importance of the neural predilection of Mycobacterium leprae in leprosy. Lancet. i:994-996. 